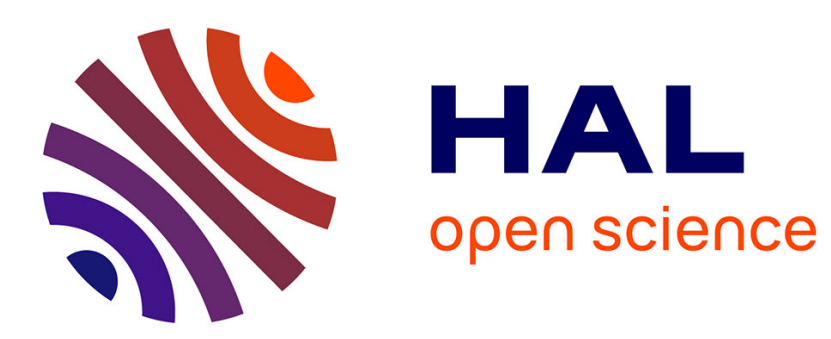

\title{
Face-to-face phacoemulsification using a slitlamp in patients who are unable to lie flat
}

Guillaume Boutillier, David Toubeau, Julie Gueudry, Marc Muraine

\section{To cite this version:}

Guillaume Boutillier, David Toubeau, Julie Gueudry, Marc Muraine. Face-to-face phacoemulsification using a slitlamp in patients who are unable to lie flat. Journal of Cataract and Refractive Surgery, 2019, 45 (11), pp.1535-1538. 10.1016/j.jcrs.2019.08.012 . hal-02955704

HAL Id: hal-02955704

https://hal-normandie-univ.archives-ouvertes.fr/hal-02955704

Submitted on 5 Oct 2020

HAL is a multi-disciplinary open access archive for the deposit and dissemination of scientific research documents, whether they are published or not. The documents may come from teaching and research institutions in France or abroad, or from public or private research centers.
L'archive ouverte pluridisciplinaire HAL, est destinée au dépôt et à la diffusion de documents scientifiques de niveau recherche, publiés ou non, émanant des établissements d'enseignement et de recherche français ou étrangers, des laboratoires publics ou privés. 


\title{
Face-to-face phacoemulsification using a slitlamp in patients who are unable to lie flat
}

\author{
Marc Muraine, MD, PhD, Guillaume Boutillier, MD, David Toubeau, Julie Gueudry, MD, PhD
}

Phacoemulsification can be challenging in patients who are unable to lie flat or sit in a reclined position that exceeds 30 degrees to 45 degrees during surgery. We describe a new technique that we have used on 4 eyes of two patients. Both were operated on while sitting in a strictly upright position, resting their chin in front of a mobile slitlamp in the same manner as during a standard ophthalmologic examination. The surgeon sits on the other side of the slitlamp, facing the patient, and operates via a temporal corneal incision. The described operating conditions were deemed perfectly adequate by the experienced surgeon. Both patients recovered a corrected distance visual acuity of $20 / 20$ in both eyes and said they would recommend this surgery to anyone who cannot lie flat. Surgeons should consider this technique when standard surgical positioning is not possible.

J Cataract Refract Surg 2019; 45:1535-1538 @ 2019 ASCRS and ESCRS

Online Video
C ataract surgery is mostly performed under local anesthesia in patients who are lying flat on their backs and are relatively calm. This position, which is ideal for the patient as well as the surgeon, is not always a viable option when patients cannot stay supine because of medical conditions (eg, orthopnea, spinal deformity, Meniere disease). A few studies ${ }^{1-6}$ reported on a technique that allows one to operate on patients sitting in a nearly upright position with the microscope inclined; however, to our knowledge, no study has suggested a technique where the patient is seated completely upright. Herein, we present a new technique that allowed us to perform phacoemulsification in two patients (4 eyes) who were sitting in a strictly upright position by using a slitlamp rather than an operating microscope.

\section{SURGICAL TECHNIQUE}

This case series comprises 4 eyes of two patients operated on in an upright sitting position for their cataract. Both patients are much more comfortable in a strictly upright position and have been refused general anesthesia by an anesthesiologist. Table 1 shows the preoperative characteristics of both patients. The procedure conformed to the tenets of the Declaration of Helsinki, and institutional review board approval was obtained. All patients provided informed consent.

\section{Patient 1}

Patient 1 has been unable to lie flat for 20 years because of extremely incapacitating dizziness triggered as soon as his back is inclined by more than 30 degrees. This patient had the surgery performed under topical anesthesia in both eyes.

\section{Patient 2}

The second patient suffers from respiratory failure and is under oxygen therapy 24 hours a day. His back cannot be inclined by more than 40 degrees. The surgeon preferred to perform a sub-Tenon anesthesia before the intervention in this patient in both eyes.

The intervention is performed in a standard operating room dedicated to ophthalmologic surgery. A mobile slitlamp (BQ 900 LED, Haag-Streit AG) that is secured on an instrument table on casters is used. It is decontaminated when entering the operating room in the same manner as the usual microscope.

The eye decontamination with povidone-iodine is carried out with the patient sitting upright in a chair, as is the sub-Tenon anesthesia when it is required. 
The slitlamp's base plate and frame are covered with surgical drapes, and the handles as well as the rollers are covered with the same type of sterile protection that is used for the operating microscope (Lumera 700, Carl Zeiss Meditec AG). The patient is then covered with a surgical drape with a hole and sits in front of the slitlamp as for any standard ophthalmic examination. The chin and forehead are then well set, and a nurse stands behind the patient to keep him stable (Figure 1 and Video 1, available at http: //jcrsjournal.org).

Once the speculum is put in place, the intervention starts with a $2.2 \mathrm{~mm}$ temporal corneal incision. The surgeon sits in front of the slitlamp, facing the patient. The right eye is operated on with the left hand, whereas the left eye is operated on with the right hand by an experienced surgeon. The ophthalmic viscosurgical device injection as well as the capsulorhexis and hydrodissection do not differ from the standard surgery procedures. The binocular slitlamp provides an excellent stereoscopic magnified view of the eye structures, which seems to be even better than the one obtained with the usual microscope. The retroillumination allows for a good visibility of the capsulorhexis. Patient 1 required Trypan blue because of a very dense cataract. Phacoemulsification was uneventful. The phacoemulsification is performed using a phacovitrectomy system (EVA, D.O.R.C. International $\mathrm{BV}$ ). The phacoemulsification settings are the same as those used for a standard phacoemulsification procedure (with the patient lying flat). The bottle height is $75 \mathrm{~cm}$ for the first phase of phacoemulsification (sculpting) and $105 \mathrm{~cm}$ for the second phase (quadrant removal). The percentage of ultrasound is up to $50 \%$ for the first phase and up to $40 \%$ for the second phase. Once the central groove is made, the surgeon uses either a monomanual technique, which is easier for avoiding contact with the slitlamp on the nasal side, or a bimanual technique after a lower nasal anterior chamber puncture is performed. When the nucleus fragments are separated, they spontaneously come forward by gravity and are very easily retrieved (Figure 2). Cortex removal and implantation do not differ from the standard surgery procedures. At the end of the intervention, the surgeon injects $0.1 \mathrm{~mL}$ of intracameral cefuroxime into the anterior chamber.

No vitreous push occurred during the surgical procedure, probably because it was performed in a nearly completely watertight anterior chamber. No bulging of the posterior capsule toward the operator was seen during the phases of sculpting and quadrant removal or during the irrigation/aspiration procedure. The only noticeable change was that lens fragments, when very hard, detached more easily toward the anterior chamber because of gravity, as can be seen in Patient 2 in Video 1 (available at http: //jcrsjournal.org).

\section{Results}

Postoperatively, no difference was noted compared with a cataract surgery with the patient lying flat. Both patients recovered a corrected distance visual acuity (CDVA) of 20/20 in each eye. Table 1 shows the preoperative and postoperative CDVA as well as the grades of cataract in both patients. Neither the patients' endothelial cell count nor their postoperative pachymetry were measured. However, no corneal edema was found. Both patients were very pleased with the intervention and would recommend this surgery to people who cannot lie flat so they can be operated on under local anesthesia.

\section{DISCUSSION}

The described surgical technique with seated positioning allowed us to operate on patients who until now had been refused for cataract surgery by an ophthalmologist and/or an anesthesiologist. Its specificity lies in our use of a slitlamp which, to our knowledge, had never been suggested before. This technique makes it possible to operate on a patient who is sitting completely upright, gazing horizontally, unlike the standard technique in which the patient's gaze is vertical and unlike other suggested techniques for which it is necessary to partially incline the patient's head to be able to use the microscope. Several quick surgical gestures are already commonly executed with the slitlamp, such as the removal of sutures after keratoplasty, the diagnostic anterior chamber puncture in patients with uveitis, or in cases of air injection into the anterior chamber in postoperative Descemet membrane endothelial keratoplasty patients. A slitlamp cannot easily be left permanently in an operating room; therefore, the best move is to transfer the mobile slitlamp into the operating room (thanks to its casters) after decontamination. Cover the table on which the slitlamp sits with two sticky surgical drapes on either side of the base unit. Then, the base can move freely because it is covered

Table 1. Details of two patients (4 eyes) who benefited from face-to-face phacoemulsification using a slitlamp.

\begin{tabular}{|l|c|c|c|c|}
\hline \multirow{2}{*}{ Parameter } & \multicolumn{2}{|c|}{ Patient 1, Male (Age 70 Y) } & \multicolumn{2}{c|}{ Patient 2, Male (Age 60 Y) } \\
\cline { 2 - 5 } & Right Eye & Left Eye & Right Eye & Left Eye \\
\hline Preop CDVA & 0.6 & 0.3 & 0.4 & 0.3 \\
Preop refraction & $+1.25+0.25 \times 170$ & $-1.75+0.50 \times 165$ & $-4.25-1.00 \times 700$ & $-5.25-0.50 \times 100$ \\
Cataract type/grade & Nuclear/grade 2 & Nuclear/grade 3 & Nuclear/grade 4 & Nuclear/grade 3 \\
Anesthesia & TA & TA & STA & STA \\
Postop CDVA (1 Mo) & 1.0 & 1.0 & 1.0 & 1.0 \\
Postop refraction (1 Mo) & -0.25 & $-0.25 \times 75$ & $-0.25-0.25 \times 60$ & $+0.25-0.50 \times 145$ \\
\hline
\end{tabular}




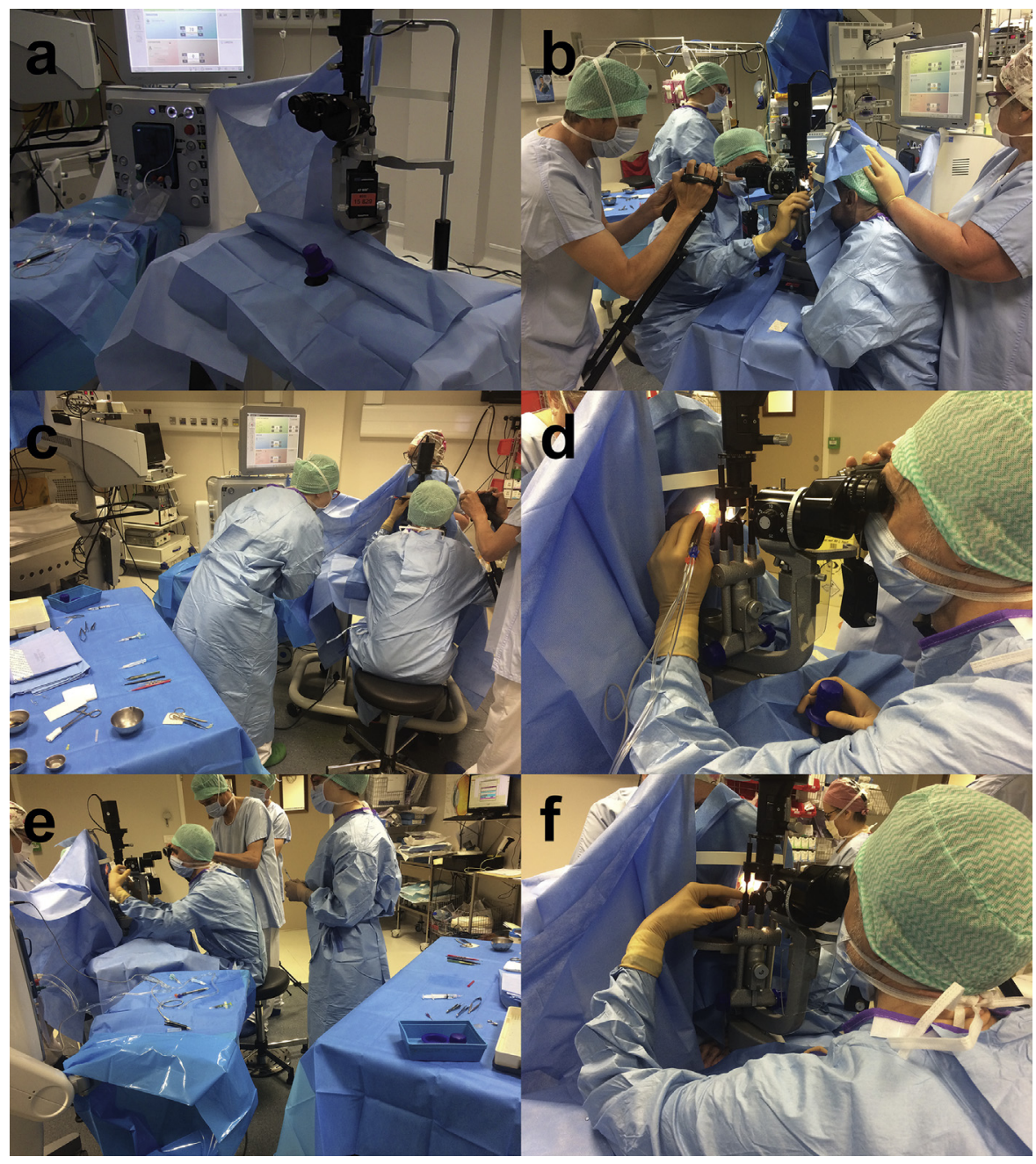

Figure 1. Position adopted by surgeon for surgery. a: The slitlamp is covered with surgical drapes and the joystick and roller are protected. $b$ : Left lateral view of the patient positioned for surgery in the right eye with the nurse standing behind him. $c$ and $d$ : Back view and left lateral view of the surgeon performing phacoemulsification for surgery in the right eye. $e$ and $f$ : Lateral and back view at the time of implantation.

with a surgical drape with a hole through which the central joystick goes.

When one works in a sterile environment as we do, with a microscope with handles that are covered with sterile protection, it is easy to adapt the protections used for our operating microscope onto the joystick and the roller for adjusting the illumination.

Several studies ${ }^{2-5}$ describe a technique that allows one to operate on a cataract patient who is sitting nearly upright with the head tilted forward. With this technique, the

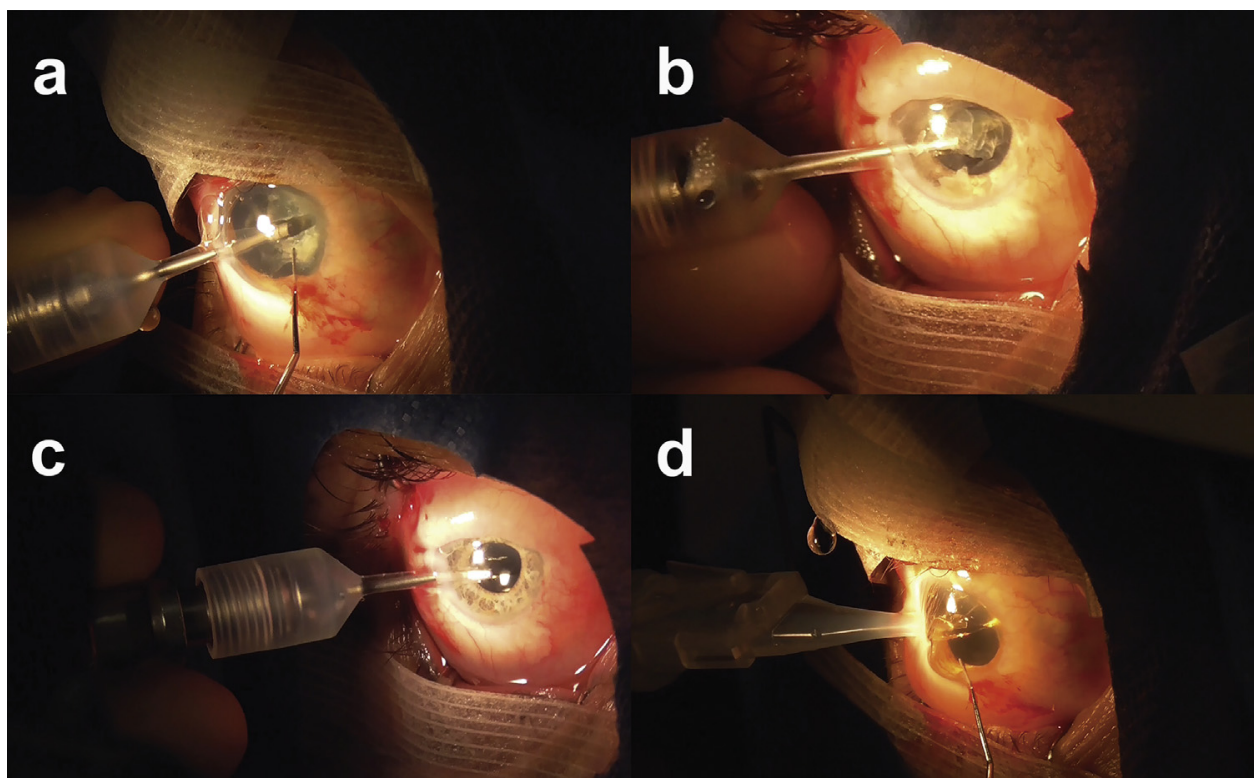

Figure 2. Face-to-face phacoemulsification using a slitlamp in patients who are unable to lie flat. $a$ and $b$ : Phacoemulsification. $c$ : Cortex removal. $d$ : Implantation. 
microscope was rotated 60 degrees from the vertical point toward the patient. The surgeon sits on the patient's right, facing the patient for a right-eye surgery, and performs an inferior incision to insert the phaco probe. However, the disadvantage of this is that the surgeon must operate at an unfamiliar angle, with outstretched arms. Although this solution is often satisfactory, there are cases in which it is not possible to even slightly incline the patient.

In our technique, the surgeon adopts a familiar position because he or she is used to working several hours behind a slitlamp, fully facing the patient, on a daily basis. Therefore, the surgeon does not have to move to the side, unlike previously reported. The optical quality is excellent, so the stereoscopic vision can be even better than that of an operating microscope. The surgery is certainly unusual and must be performed by an experienced cataract surgeon, especially because the right eye must be operated on with the left hand and the left eye with the right hand. This has not been an issue for us: similar to many other surgeons, we are used to operating in right eyes with the right hand and in left eyes with the left hand when the patient is lying flat.

One of the specificities of this surgery with strictly upright seated positioning is that lens fragments automatically dislocate forward (toward the anterior chamber) when they detach from the bag rather than being projected backward. This makes their aspiration and emulsification easier. In addition, we can imagine that in the case of a posterior capsular tear, there would be very few risks for lens fragments falling into the vitreous cavity and an anterior vitrectomy would be feasible through a corneal incision.

In our technique, the patients lean on the chin rest and head rest, which stops them from moving forward, and they are helped and stabilized if needed by a nurse standing behind them, which we find very reassuring. In addition, if some difficulty in positioning occurs, the patients can move back for a few dozen seconds and then resume their position for the remainder of the surgery. We felt this surgery could be suggested by an experienced surgeon to any patient preferring a sitting position to a supine position and that the risk for capsular tear was not higher than in standard surgeries. Designing a resting support for the surgeon's elbow could further improve the operating conditions. In this way, the technique we present is reminiscent of the surgical positioning used by Jacques Daviel in 1745 when he presented an extracapsular cataract extraction for the first time. ${ }^{7,8}$ He was then sitting face-to-face with the patient and operated in the right eye with his left hand and in the left eye with his right hand.

\section{WHAT WAS KNOWN}

- Phacoemulsification can be challenging when patients cannot stay supine because of medical conditions (eg, orthopnea, spinal deformity, Meniere disease), and a few patients are unable to sit in a reclined position that exceeds 30 degrees during surgery.

- Techniques published in the literature have suggested using a standard overhead microscope to operate on patients sitting in a nearly upright position, with the microscope inclined.

\section{WHAT THIS PAPER ADDS}

- This new technique enabled surgeons to perform phacoemulsification in two patients (4 eyes), who were sitting in a strictly upright position, by using a slitlamp rather than an operating microscope.

\section{REFERENCES}

1. Rogers GM, Goins KM. Cataract surgery in the patient that cannot lie flat Curr Opin Ophthalmol 2010; 21:71-74

2. Pajaujis M, Injarie A, Eke T. Extreme face-to-face positioning for cataract surgery with patient seated upright in motorized wheelchair. J Cataract Refract Surg 2013; 39:804-805

3. Ang GS, Ong JM, Eke T. Face-to-face seated positioning for phacoemulsification in patients unable to lie flat for cataract surgery. Am J Ophthalmol 2006; 141:1151-1152

4. Sohail T, Pajaujis M, Crawford SE, Chan JW, Eke T. Face-to-face upright seated positioning for cataract surgery in patients unable to lie flat: case series of 240 consecutive phacoemulsifications. J Cataract Refract Surg 2018; 44:1116-1122

5. Lee RMH, Jehle T, Eke T. Face-to-face upright seated positioning for cataract surgery in patients who cannot lie flat. J Cataract Refract Surg 2011 $37: 805-809$

6. Fine $\mathrm{H}$, Hoffman RS, Binstock S. Phacoemulsification performed in a modified waiting room chair. J Cataract Refract Surg 1996; 22:1408-1410

7. Galst JM. A look at the past. Jacques Daviel, 1693-1762. Arch Ophthalmol 1998; 116:486

8. Daviel J. On a new method to cure cataract by extraction of the lens. $\mathrm{Br} J$ Ophthalmol 1967; 51:449-458

Disclosures: None of the authors has a financial or proprietary interest in any material or method mentioned. 